\title{
Stability and Instability of an Economic System: Considerations
}

\author{
Giovanni Antonio Cossiga ${ }^{1}$ \\ ${ }^{1}$ Università Sapienza, Roma, Italy \\ Correspondence: Giovanni Antonio Cossiga, Università Sapienza, Roma, Italy. E-mail: g.cossiga@alice.it
}

Received: April 28, 2017

Accepted: May 12, 2017

Online Published: June 13, 2017

doi:10.5539/res.v9n3p8

URL: http://doi.org/10.5539/res.v9n3p8

\begin{abstract}
The essay would like to investigate on the inflation as an equilibrium problem within an economic system hit by an outside or inside shock. The persistence of economic system instability makes the inflation speed to grow, gradually reaching the maturity condition. From this point forward, the nominal price movement becomes regular and this regularity will allow the economic system to have an almost-normal working condition. The inflation must be intended as a remedy spontaneously applied when a system is hit by a severe shock, then becoming unstable. According to this view, also the negative inflation or deflation should be regarded as a spontaneous remedy, usually appearing in the world of economy to face a financial crisis caused by a speculative bubble outbreak. In this case, deflation seems to be the mere consequence of a severe economic downturn, which activates a negative inflation. The negative inflation caused by the decline in the economic situation, does accumulate inside the system and therefore is creating a progressive settlement of structural inflation. The deflation is strictly related to the depressed economy (recession), just similar to the link created between typical inflation and economic cycle. When going out from the recession, the economic recovery leads to a deflation gradual mitigation. If the economic recovery is fuelled by strong amount of public resources, it could be demonstrated that the increasing amount of public debt is neutral on the deflation destiny.
\end{abstract}

Keywords: unstable economic system, inflation, deflation, economic cycle, public debt

\section{Introduction}

\subsection{Some Notions on Economic Stability and Instability}

The stability inside an economic system can be defined as the natural state in which: 1) the potential of the economy is maximized; 2) the price system tensions are weak; 3) the economic development follows a tendentially growing line. We can therefore define the instability as the economic system unnatural state that: 1) weakens the development potential; 2) induces tensions within the price system; 3) imposes a cyclical character to the economy, with a tendency to depression if the instability is becoming persistent.

The stability is the natural condition of economic systems; the unstable state is a suffering condition for an economic system, unfortunately widespread for the behaviours (repeated human errors) contrasting a consistent development.

The unstable state of the economy differs from the stable economy scenario for the phenomena, autonomously developed, caused by the systems natural tendency to the stability. Therefore, events such as inflation, deflation and the cyclic motion of the economy, reasonably are to be considered as natural emanations occurring with the concrete goal to bring the systems back to normality.

The intensity of the phenomena developing within an unstable economy is depending mainly upon the persistence over time of these phenomena. The system, looking for a way to bring the economy back to the stability natural condition, sometimes could appear also inconsistently shaped when compared with the sickness state of the economy. These anomalies seem to be linked to the human passivity or even ineptitude to strongly face the status quo leading to a weak and fragile economy. At this stage, due to the prolonged passivity and persistent instability, the crisis can take an unusual form quite near to that indifference shown towards the economic condition. In this sense, the speculative acceleration can be interpreted as a final opportunity for the correction of the altered system.

Paradoxically, during the accelerated speculation phases, the main variables are moving in a coordinated way: falling inflation and slightly rising growth, although one or more sectors of the economy are accelerating, 
without any apparent relationship with the real economy. A completely abnormal condition that ambiguously brings the economy, on the wings of an apparent normality, to the verge of a financial crisis: therefore, this crisis would clean up the system from the error accumulation, with serious social consequences.

In the following pages, we will examine the performance of the main variables and in particular of the economic cycle and the connected inflation cycle (deflation), also giving evidence to extreme situations. We will focus then on those natural remedies that can intervene on unstable economies for a gradual return to stability and we will investigate on the possible intervention ways, considering the damage resulting from obstacles interposed on the way to a natural correction. Finally, we will try to demonstrate, with the help of econometric models, the reliability of the above-mentioned statements about the main variables performance.

\subsection{The Underworld of Economic Instability}

When a system has become unstable, the economy-naturally following a linear development-is transformed, assuming a cyclical trend. The process through cycles is the first indicator that some distortions have occurred in the previous conduct of the economy. The linear development of the economy, without the conjuncture alternated rhythm, should be indeed the natural condition. However, multiple shocks are produced for the tendency, too often not solidaristic but selfish, of individuals, institutions and national states, finally provoking errors that hamper the development path.

The world where is entering an unstable economy is therefore a different world with its own rules, alien from those of the stable condition. A kind of underworld which, for the evident diffusion of the instability virus, could be interpreted even as the normal state of the economy. Instead, it should be noted that inside an instability context the configurations assumed by the economy are just the consequence of the instability virus presence within the economic system. Like saying that all manifestations somehow typical of the unstable environment, such as inflation, deflation, economy cyclical movement, rising unemployment, recessions or depressions, are all symptoms of the same disease. Above all, it must be stressed that they are not the cause of the disease afflicting the system, since the cause of the disorder and serious damages at social and economic level as well, are lying in the mistakes that led the system to fall into the unstable underworld.

The fight against symptoms can give controversial results. However, when I take an analgesic to have certainly some temporary relief, nothing will happen about the causes provoking the organism sickness. It is therefore quite strange to pretend that unstable economy could be cared through symptom control, for example fighting against the rising inflation. There is no doubt that some appreciable result can certainly be reached by manoeuvring on the interest rate. With the intervention of a restrictive monetary policy the economy is freezing, causing an inversion in the economic cycle. These policies are somehow "blind way", because are just shooting for the middle, usually causing an increase in unemployment, but their real effects on the system instability reduction remain uncertain. Instability reduction is the real goal of the manoeuvres.

We risk confusing cause and effect when trying to control the inflation pressure through restrictive manoeuvres or labour market limitation, because the goal is not the mere inflation control (the system fever). Fever is a defence tool, being part of the natural mechanism protecting an organism from disease. Like the fever, also the inflation must be considered as a natural mechanism that the economic system turns on just to give a message on the economy trouble.

Therefore, it may not make any sense or even could be altered the context if the fiscal policy would attempt to reinforce economic recovery after a recession. Indeed, the conjuncture with its phases are the sub-product of the system instability, as events activated by the natural mechanism for the return to stability. Acting with pro-cyclical actions can contrast the natural mechanism for the recovery of the instability state, so leading to unexpected results.

Similarly, doesn't make sense the idea to activate an inflation revival to release the deflation pinch. In fact, inflation and deflation are not opposed mechanisms but monetary phenomena that have a same common matrix: the economy instability. These phenomena are reflecting, at monetary level, all the economy uncertainties and the errors accumulation that have derailed the system from the correct path on the stability ground. In specific terms, as inflation is the symptom of a more or less severe instability, the proposal to face deflation by creating more inflation is the only way to produce new errors. It should be added that in case of deflation, increasing the level of errors would only produce greater deflation and never more inflation. 


\section{Method}

\subsection{The Relationship between the Cycles and the Main Variables within an Unstable Underworld}

Inflation and deflation do not have a rational human direction, as they are the outcome of errors contaminating the economy normal and natural trend. Inflation or deflation, within an unstable system, are a modality of monetary kind which is activated in an autonomous and independent form, following a pattern repeated over time. Inflation and deflation are cyclical phenomena, closely linked and related to the economic cycle.

Despite the disturbances caused by the unstable state, it should be noted that during the development of the inflation or deflation phenomenon, the economic system shows to be able to operate in almost normal conditions. This feature is crucial for the systems because it works as a functionality guarantee, even with severe instability in market mechanisms. This potential of the system seems could be attributed to the peculiar regularity in the development of inflation. With or without limited interventions, the trend of nominal prices outlined by inflation is moving quite uniformly, and this allows the exercise of future price forecasts, according to the observation of the past. This predictability of nominal price motions is the guarantee for the economic system functionality, even in conditions of ongoing instability (high inflation or severe deflation).

The unstable condition is the fall of the economic system in a sort of parallel sub-world, anomalous and different if compared to that of the stable condition in which, however, the altered economic system can maintain as much as possible its operational functionality. This configuration, so reassuring, could justify the innate ability of economic systems to follow in the long run a path of economic growth, despite the accumulation of human errors over the centuries (wars, starvation, internal and external shocks).

The regularity of inflation (deflation) is a direct consequence of the cyclical movement inside an unstable economy. The regularity of the unstable economic trend rate, observed by Schumpeter, is the container where the cycle of nominal prices is formed and shaped, in the same way regular or at least predictable.

The scenario in which is moving and is shaped the unstable system economy has peculiar characteristics, different from those of the stable economy. Cyclical waves that shape, with quite regular cadence, the market trends; waves at the same time feeding the inflation trend (deflation). The economy, moving according to the economic cycles, certainly cannot be causal and produced by the chaos. Conversely, this must have its own purpose. A purpose which is undeclared and unmotivated in the stability world, where the cycles and the rhythmic motion of prices should be inadmissible.

This purpose in the cyclical-shaped economy underworld must be linked to the stability principle. The stability principle of economic systems can be adopted as a permanent phenomenon in the economic sphere. With its adoption as a paradigm we are able indeed to give a justification to the long uninterrupted journey of human societies on the path of economic development and knowledge, despite all the errors repeated during the whole human history.

If we accept the stability principle as a necessary corollary for the humanity proceed in the history, we should believe that consequently must exist in the market some natural forces, able to push the systems through the instability route, to the final port of stability. The structure crossing the market with its cyclical waves, in case of instability, must be interpreted exactly as a natural system for the human error correction, a way for a gradual return to stability. Obviously, mercy works in mysterious ways, nevertheless it isn't moving following immediately understandable ways.

Inflation is often the track on which market expectations are moving, but the key to the problem configuring the unstable underworld is firmly held by the cyclical conjuncture, which is imposing regularity to the economic context, otherwise condemned to chaos. In other words, the anxiety about inflation might not be so disturbing, because the issue that should worry the authorities is the economy cyclical motion: the more irregular, the more severe will be the system instability.

According to this approach, inflation is not the disease; it is rather a symptom of the economic system disease, the instability of the economic system. The attempt to hit the image instead of the real responsible, namely the instability and the economy cyclical movement, sometimes can become misleading and moreover can provoke unexpected results. Inflation is reflecting as in a mirror the altered market movements in an unstable system; trying to hit the image in the mirror is like believing that we can enter into the mirror as in fairy tales, so dealing with the images. 


\subsection{Anomalies in the Underworld of the Economic System Instability}

Given their nature of monetary phenomena, inflation or deflation are not opposing phenomena, but somehow connected for being the multifaceted expression of instability in the economic system. It is a widespread idea that inflation, like a sleeping virus, may awaken with the absence of control measures. The endemic story of recurrent inflations seems to draw to the conclusion that inflation may be an unavoidable and insuppressible event, accompanying any economic system.

This is an archetypal vision, a sort of recurring litany, basically lying on the superficial examination of the phenomenon. A long time stable economic system cannot be subject to cyclical movements in the economic conjuncture profile, as well as in the price system. Significant fluctuations in international prices (e.g., oil prices) may induce alterations to the economic trend and to the nominal prices even in stable systems. These troubles in the growth process in stable systems, due to some shock for changes in international prices, are not cyclical movements and therefore recurrent but instead temporary movements of a country internal balance reassessment.

Stable systems are subject to a developing trend going in a straight line with a slope depending on potential. A shock coming from outside can induce a change in the potential, in other words a variation on the inclination of the economic growth line, not provoking any kind of cyclic movement nor on the economy nor on the price system. Nevertheless, within a stable context it is to be ruled out any eventual cyclic variation in the prices, since it is quite unlikely that, in absence of shocks, the economy could assume a cyclical movement, so experiencing for example the symptoms of a recession and therefore of a deflation.

Inflation and deflation are natural events, peculiar and typical of an unstable system. There is no doubt that the start up of these monetary phenomena is provoked by any kind of error, from mismanagement to uncontrolled selfishness of individuals and institutions, and by tragedies such as war, persecutions, etc., all events deviating the economic system away from the natural path for compatible growth.

The experience seems to show that the system instability is calling the inflation (considered as acceleration of nominal price speed) or the deflation (considered as decline and reduction of nominal prices), following an effectiveness principle of the intervention on the altered system. We can consider the natural corrective action as a factor following the line towards the efficiency and compatibility of an economic system, because even during the unstable condition nothing is left to a blind causality.

This is because the natural mechanism that oversees the stability of economic systems, is activating a progressive strategy that over time could make unsustainable to continue without correcting all the accumulated errors. If, despite the intensification of social and economic damages, the inertia persists at the error correction level, then will be the natural play of the recession with its related monetary phenomena-even more rough and costly in social terms-to try to find some remedy for the deteriorated situation.

\subsection{A Few Examples May Help the Analysis of This Theme}

In the seventies, the long wave of post-war development was exhausted and any attempt to maintain the high growth trend has sown the inflation seeds in the western area. In 1975 therefore, the first oil shock found a breeding ground to start an unexpected price run. In a stable system, the wave of increases related to changes in international prices tends to fade, after provoking nevertheless a reduction trend in income. When there are improper decisions (e.g., the attempt to maintain a pre-shock living standard level), can occur (as in fact happened) a nominal price acceleration, if the inflation seeds have already been sown.

In the first decade of this millennium, some joint mistakes of monetary and fiscal policy have started repeated phases of speculative acceleration, supported by "creative finance" which mobilized resources incompatible with the underlying real economy. Since the beginning of 2000 until 2007, we have witnessed various progressive speculative accelerations, up to the residential real estate boom, which involved most of the world economies. It has been a long period of exuberance not connected to the real economy, during which there has been a gradual disintegration of the hard core of structural inflation, though the speculation has accelerated the oil prices (from $\$ 30$ in 2000 to $\$ 145$ a barrel at beginning of 2007). The eruption of the most powerful speculative bubble since the $30 \mathrm{~s}$, has started a deflation exacerbation in those countries financially most vulnerable. Deflation has been favoured, because at the top of the speculative boom, the structural inflation was close to zero. A similar trend occurred at the end of the eighties in Japan, with a zero inflation in 1985 and a creeping deflation together with low growth that characterized the "country of the Rising Sun" for over twenty years.

The chain of errors, which causes a serious instability, can also degenerate when it's hampered or even blocked the natural mechanism for the return to the stable condition. In this deplorable situation, may happen that the connection established between the economy depressed cycle and the subsequent tendency to deflation of the 
price system, could play its role not only in the direction from the economy to deflation, but also in reverse from the deflation to depressed conjuncture in the economy. A serious anomaly which is worsening the already serious economic trouble.

During the correction phase of an unstable system, the link between the economy and the price system is usually one-way. The relationship between the economy and inflation (deflation) is always proceeding from the conjuncture (in deep depression during the financial crisis) to the falling prices. It is neither possible nor acceptable that there could be a feedback from the falling prices towards the economic conjuncture, which accentuates the economy depression. Prices are the image of the conjuncture situation and they follow her destiny in a neutral way, not being able to interfere in any way with the state of the economy.

This absolute rule allows however an exception, as demonstrated during the 1929 crisis. During the severe deflation following the Stock Market collapse and the financial crisis, the deep depression of the economy was accentuated and extended by the rigidity of Gold Standard Interwar (again adopted by the world's major economies after World War I).

On that occasion, monetary rigidity has tragically accentuated the depression. A vicious circuit has been created, self-powered on one way through conjuncture and deflation tied to the economy, and on other way through the economy and the nominal price fall tied to the Gold Standard Interwar. A specific monetary factor (the monetary rigidity), which therefore made bidirectional the relationship between economy and deflation, relationship usually going one-way from the economy to the prices. An error that from the currency (linked to the Gold Standard Interwar) has moved sic et simpliciter to the economic level, thus inhibiting also the normal economy correction entrusted to the natural mechanism. Therefore, not only the monetary error has exhausted the economy for a ten-year period, but also blocked the natural correction action, so extending forward in time the system trouble fighting with an unsolved financial crisis.

A perverse link that only dissolved when the (late) decision was taken by USA and European countries, to abandon the Gold Standard. A decision adopted by UK only in 1933, followed by the United States the year after. However, France resisted until 1935 because was strong the attraction of that country on the world gold movements and this had assured large gold reserves.

Ben Bernanke, former Federal Reserve president, examined through detailed analysis the events that followed the 1929 crisis, focusing with particular emphasis on the relationship between economic depression and price deflation during the thirties.

In the Tables 1 and 2 (Ben Bernanke, 2000) data relating the wholesale price trend and the industrial production, both expressed in terms of Log differences on previous year. The sequence shown in this table is listing the countries with the dividing line of the Gold Standard withdraw time. This kind of subdivision should allow us to appreciate the effects of monetary restrictions imposed by the Gold Standard, relating to wholesale prices (deflation) and to industrial production trend (proxy of the economy).

Table 1. Countries not on Gold Standard or leaving prior 1931 and in 1931*

\begin{tabular}{cccccccc}
\hline \multicolumn{7}{c}{ Log-differences of Industrial Production } \\
\hline 1930 & Spain & Australia $(1929)$ & Canada & Germany & Japan & U. K. & Average \\
1931 & -0.01 & -0.11 & -0.16 & -0.15 & -0.05 & -0.08 & -0.05 \\
1932 & -0.06 & -0.07 & -0.18 & -0.24 & -0.03 & -0.1 & -0.12 \\
1933 & -0.05 & -0.07 & -0.2 & -0.24 & 0.07 & 0 & -0.07 \\
1934 & 0.01 & 0.1 & 0.04 & 0.13 & 0.15 & 0.05 & 0.08 \\
1935 & 0.02 & 0.09 & 0.2 & 0.27 & 0.13 & 0.11 & 0.13 \\
1936 & & 0.09 & 0.1 & 0.16 & 0.1 & 0.07 & 0.1 \\
\hline
\end{tabular}

*Austria, Canada, Czechoslovakia, Denmark, Estonia, Finland, Germany, Greece, Hungary, Japan, Latvia, Norway, Sweden, United Kingdom. 
Table 2. Countries abandoning Gold Standard between 1933, 1934 and 1936*

\begin{tabular}{ccccc}
\hline \multicolumn{5}{c}{ Log-differences of Industrial Production } \\
\hline & United States (1933) & Italy (1934) & France (1936) & Average \\
1930 & -0.21 & -0.08 & -0.01 & -0.04 \\
1931 & -0.17 & -0.17 & -0.14 & -11 \\
1932 & -0.24 & -0.15 & -0.19 & -0.17 \\
1933 & 0.17 & 0.1 & -0.12 & 0.1 \\
1934 & 0.04 & 0.08 & -0.07 & 0.02 \\
1935 & 0.13 & 0.16 & -0.04 & 0 \\
1936 & 0.15 & 0.07 & 0.07 & 0.06 \\
\hline
\end{tabular}

*France, Netherlands, Poland.

Note. Data on whole sale prices are from: League of Nations. "Monthly Bulletin of Statistics" and "Yearbook", various issues. Dates in brackets are years when countries abandoned gold, with the "abandonment" defined to include the imposition of foreign exchange controls or devaluation and suspension as well. Table elaborated with data taken from: Ben Bernanke. "Essays on the Great Depression" (2005).

\section{Results}

\subsection{Considerations on the Instability Correction Topic}

Deflation and inflation are not opposing phenomena, but rather peculiar symptoms of the instability state, caused by behaviours against the market that derailed the economy train from the path of a balanced and compatible growth. Inflation and deflation are to be considered as faces of the same medal, though each one with own specific properties.

The correction of unstable systems-as already said-is untrusted to economic cycle. The positive or negative inflation parallel cycle is to be considered just as a crisis thermometer. It's therefore not a kind of medicine for the instability crisis, but simply a meter, a signal for the unstable state of the system. Therefore, the crisis monetary parameters, expressed by inflation or deflation, cannot give a specific contribution for the care of the altered system; this care is lying primarily on the correction force of the conjuncture cycle. Deflation or inflation cannot be considered as enemies to be opposed. They are instead premonitory messengers, inducing the authorities and operators to take corrective actions and policies, before the natural corrective action could do more damages to the social and economic structure.

These monetary phenomena (inflation or deflation) are like "puppets" in the theatre of the economy, directly animated by the economic conjuncture in an unstable system. They are, therefore, completely missing any behaviour autonomy and therefore are unable to play any actual antagonistic role against the real enemy, the instability. A battle at monetary level to control inflation and deflation could be just a battle against the windmills. Only if monetary policy is able to facilitate a recovery at the economy level, it can have significant results though indirectly also at the monetary level.

Essentially, when we choose to follow the natural path for the instability reduction (through reversal of the economic cycle), we're trying in practice to balance the economic system, nevertheless we don't eliminate the errors causing instability. The correction through the recession is very harsh on the social as well as on the economic level, because in this way we're trying to fix the system leaving out the elimination of those errors which are the instability responsible.

The real problem of the unstable system correction is the elimination or at least the reduction of the errors that have dragged the economic system out of the natural way. The governments, the market operators and the families must take note and accept all the sacrifices necessary to correct the status quo. It is in any case a brave position that will be rewarded in terms of lower social discomfort, compared to that which otherwise would be necessary to pay in case of inertia and, consequently, of the unavoidable intervention through the natural correction way of the economic system.

The German economist Schumpeter did speculate about the "creative destruction" function performed by the recession. The thesis of the famous economist can be updated in the sense that the economy is reaching the creative recession stage not only to facilitate the system technological renovation, but rather to remove the 
instability causes traumatizing the system. The mechanism leading to the reversal of the economic cycle, therefore, would have the salutary task to put back on the right track the social and economic development train, after the derailment of the unstable system.

It is reasonable at this point to argue that the natural tendency to equilibrium and stability of the economic systems, confirmed by the long development process of human societies, should involve an important consequence. The economic systems tend to stability because they possess a connatural ability to redress the economic mechanisms, distorted only due to human errors.

Since the cyclical movement of the economy is a typical character of the economic system unstable state, it should be just the cyclical movement the right engine which is required to manage the phases, often unclear, to bring the deviating system again on the stability and compatible growth route.

At this point we should argue that the cyclical movement running inside the unstable economy not only isn't causal, but also must pursue the goal to remove the causes of instability from the altered system. This is another reason why it is unacceptable that the cyclic wave may invade a stable system. Indeed, the absence of any reason for starting a system correction, implies that are not required-or even worse, unnecessary-the economic cycles for the correction of a healthy economy.

The conjuncture and inflation cycles, linked to economic fluctuations, are spreading without restriction inside an unstable system. The recovery of the cyclical economy is empowering a cyclical inflation which is periodically accumulating inside the system, so creating a structural inflation. During the economic cycle recession, it's spreading instead a negative inflation, linked to the declining conjuncture. The forming of this negative inflation, produced during the recession, plays in subtraction from the structural inflation accumulated during the cycle growing trend. In case of a persistent instability, the recession is prevailing and is intensifying during the cyclic sequence. Therefore, a negative cyclical inflation it's created, acting in subtraction from the structural inflation, until to invert the otherwise rising system inflation.

\subsection{The Natural Correction Mechanism}

Once left free to act, this natural correction is the equivalent, regarding the effects, of a restrictive monetary policy pushing the system towards a controlled recession. The success or failure of this correction is sanctioned by the inflation response. The correction would end when the inflation returns low and remains low for a long time, while the economy is resuming its linear trend.

A classic example of recession cleaning the system from inflation and putting the economy back on the right path can be observed in the USA during the first term of the Reagan Presidency. As we can see in the Figure 1, during the seventies the United States are suffering, like almost the whole industrialized area, for high inflation fuelled by the decade oil crises. At the beginning of his presidency, Reagan starts a deep disinflation, with a marked tightening of monetary policy (in 1981 the interest market rate rises up to 14\%). The US economy undergoes a controlled recession (-2\% for the 1982 GDP), but recovers gradually marking a $6.5 \%$ only two years later, in 1984. As a result, inflation decreased from the $12 \%$ of 1980 to the $5 \%$ of 1982 , to touch the $2 \%$ during following years. It should be noted that during those years, the fiscal policy is maintaining its efforts to support the economy, as well evidenced during the eighties by the public debt increase, namely from $40 \%$ at the decade beginning to $60 \%$ at the end of period. 


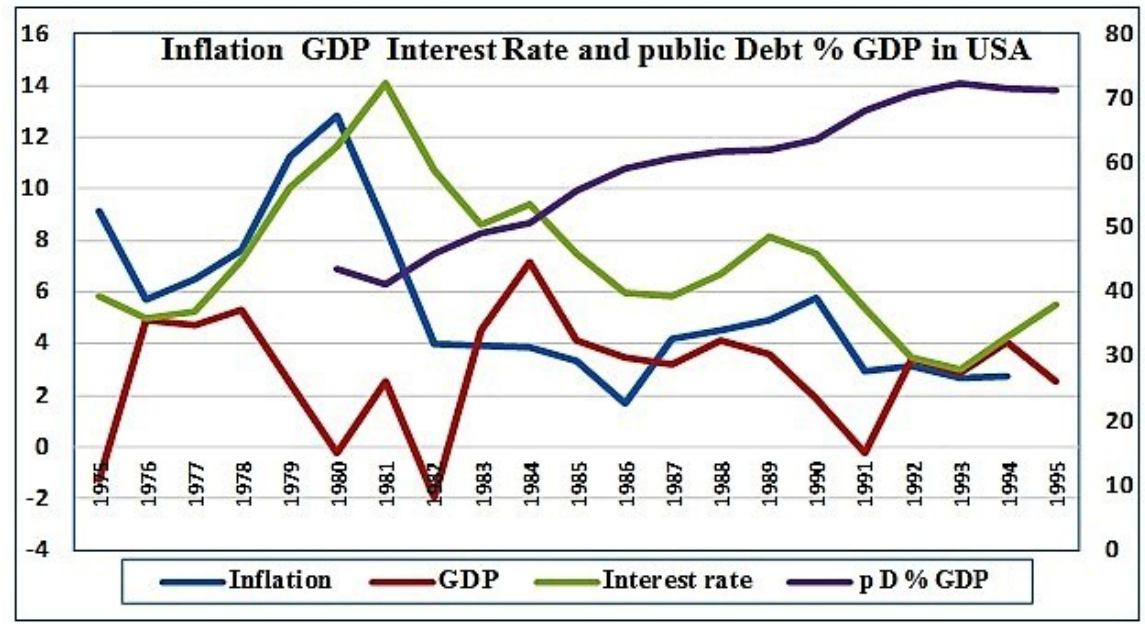

Figure 1. Inflation, GDP, interest rate and public debt in \% GDP in US

Source: based on data from IMF_- "International Financial Statistics", several years.

In the event of inertia or inadequate response from the economic system, the natural correction mechanism could continue to intensify its action. Basically, the economic recession phase is prolonged and intensified, while the active recovery phase of the cycle almost disappears. In general, the acceleration of the inflation phenomenon, until the hyperinflation threshold and even beyond, occurs when, beside the inertia in facing the phenomenon, decisions are taken that are contrasting the instability correction natural process.

The economic system, both in case of hyperinflation as in case of intolerable speculative acceleration, seems to follow the adage "the worse, the better", in case of incredible tolerance and inactivity of governments, business people and families. Like saying that, after the use of all possible means to indicate the faults produced by errors on the economic functionality, the corrective system may cause an uncontrollable event creating an absolute need for intervention to calm things down. At the end, what is left is a very serious financial crisis which, in both cases, will surely produce very serious social and economic damages, in addition to heavy aftermaths that may last more than a decade. In other words, if an economy is unstable for a long time it is possible the accumulation of a high structural inflation. According to the natural mechanism, inside a system with inflation the return to the stable state is requiring the creation, through a recession, of a negative structural inflation offsetting the positive one created during the unstable state. A worrying way, however making clear to the market how much the system is unstable, through the acceleration of inflation mechanism, and moreover making people aware about the growing difficulties for the return of the system to its natural condition.

Instead, in the case of deflation always due to instability, the recessive process affecting the economy for a financial crisis, produces the opposite effect. Gradually, the financial crisis hits the virtual abundance created by speculative excitement, sweeping away from the altered system this virtual product which is not compatible with the real economy. A recovery in the economic cycle is the signal that the correction is starting to rebalance the system and consequently also the deflation is loosening its grip.

It may be deduced that the penalties required by the natural correction can be more painful and difficult for the economic and social structure, if compared to those incurred when starting the removal of the accumulated errors with appropriate corrective policies. In fact, it should be considered that the natural correction must be more drastic because a new stable equilibrium must be reached, without removing or removing only partially the errors from the system, with the evident consequence of additional social costs.

At this regard, it's necessary to emphasize that in case of inflation or deflation, the system seems to announce in time to the operators that some errors are jamming the normal functioning of the economy. This notice, in both cases (inflation or deflation), with its signal is often giving quite time for any possible intervention by the authorities to clean up the unstable system, so causing only a small social damage. In the case of inflation, this time-during which the cost of intervention is minimized - would end when the inflation move begins to accelerate. In the case of deflation, the intervention time at the lowest cost is exhausted when the formation of the speculative bubble becomes noticeable because the trend in nominal prices is basically deflationary. 


\subsection{The Case of Austria during the Post-First World War}

To remove all errors accumulated in the past certainly are required courage and determination, as well as great communication skills to be able to explain the choices made for the country's government. In any case, regarding the costs for the collectivity, taking the initiative for corrective work and then for the return to the economic system stability is always the action to be preferred, compared to that of inertia and expectation.

At this regard, it may be useful to recall the case of Austria during the post-First World War. At the end of the war, Austria is one of the countries emerged from the Austro-Hungarian Empire. It follows the same destiny of Germany, undergoing a serious hyperinflation. Also in the case of Austria, with the creation of a new currency there was a sudden stabilization and an immediate stop to the torrential hyperinflation. To achieve this result, really unexpected at that time, the Austrian government accepted the hard conditions imposed by the Council of the League of Nations. Essentially, the Austrian Government accepted a drastic reduction of the public deficit. It should be considered that the Austrian public budget, after the December 1922 stabilization, radically improves its state, limiting the 1923 deficit within 82 million shillings and envisaging 90,6 million of surpluses for 1924 and 167 million for 1925 .

Table 3. Austrian Budgets, 1919-1922 (in million paper crowns)

\begin{tabular}{lcccc}
\hline & Receipts & Expenditures & Deficits & $\begin{array}{c}\text { Percentage of Expenditures covered } \\
\text { by New Issues of Paper Money }\end{array}$ \\
\hline January-30 June 1919 & 1,339 & 4,043 & 2,704 & 67 \\
July 1919-30 June 1920 & 6,295 & 16,873 & 10,578 & 63 \\
July 1920-30 June 1921 & 29,483 & 70,601 & 41,118 & 58 \\
January31-December 22 & 209,763 & 347,533 & 137,770 & 40 \\
\hline
\end{tabular}

Source: The End of four Big Inflation (1983).

In other words, with their correction all errors accumulated over the years of the great hyperinflation (public expenditure financed by an abnormal issue of paper money) were cancelled, though with very serious social costs. The economic system stability was restored on the date fixed for the new currency issuance, so allowing the recovery of a sustainable growth. The elimination of errors that had caused hyperinflation implied not only the sudden stabilization of the currency, then apparently contradicting the money quantitative theory, but also the escape of the Austrian economy from the long period of recession together with the gradual growth recovery compatible with the evolution of the European economy at that time.

\section{Discussion}

\subsection{Deflation and Financial Crisis}

In case of deflation, the natural corrective function must unfortunately rely on the deeply adverse economic cycle, imposed by the financial crisis, which is cleaning the system from the excesses accumulated due to the errors. Even in case of deflation, the economy's health condition remains the true arbiter of the future profile assumed by nominal prices.

In an economy subject to a financial crisis, deflation of nominal prices is the parameter and the system temperature, while the recession is the index or the economic malaise sounder. The return to stable condition is requiring a high cost, which doesn't seem to be by-passable by interposing obstacles to the healing work performed by the recession.

As already mentioned earlier, during the boom preceding a financial crisis the economy shows a clear tendency towards deflation. This deflationary behaviour is suggesting that also the real economy undergoes a latent recessive trend, although the speculative exuberance is masking the real condition of the unstable system. It can be deduced reasonably that the virtual growth share fuelled by the bubble does not affect the destiny of nominal prices, which is linked instead to the real economy. In other words, the fever-negative in this case of the economic system during the speculative phase is specularly represented by the structural inflation decreasing until to touch almost the zero. The weakly deflationary price trend during the speculative phase is suggesting us that the economic growth is only virtual, that is to say generated by the speculative emphasis and therefore will be deleted completely by the incoming severe recession. 
During the financial crisis, price deflation is tied almost exclusively to the negative economic conjuncture. On the basis of this relationship, the deflationary process cannot be considered a direct and immediate consequence of the M3 contraction accompanying the crisis, but a consequence mediated by the strong downturn in the economic scenario.

In case of financial crisis, M3 undergoes a sharp contraction on its profile, which doesn't seem to have any influence on the nominal price fall. In fact both variables, price trend and M3, suffer in parallel the same tension, resulting from the adverse economic cycle. In these difficult circumstances, the intervention of the Central Bank to support liquidity within the economic system can mitigate the pressure on the deep fall in prices, but always and indirectly through the relief received by the economy, otherwise strangled by the lack of liquidity. All the above is not surprising because, given the close relationship between economy and deflation, the engine moving the couple of the two variables (prices and M3) is always the conjuncture. Only the improvement of the economic situation, therefore, can ease the downward pressure of prices and therefore would raise up the M3 profile.

Then, during the financial crisis, the economic conjuncture is sending one-way messages to nominal prices, which will follow the same destiny. The prices reflect as in a mirror the falling values of the economy in crisis. We're not in a fairy tale, so in the mirror there is no life that could be transmitted, but only reflected images of the real world of economics. The economy-price relationship, in the case of the financial crisis, is working as a mitral valve. The economy flow passes through the valve towards the price mechanism, but the price system cannot interfere with the economy flow, because the valve is preventing the backwards passage.

\subsection{Deflation and the Measures to Support the Economy}

This peculiar mechanism may explain why the economic stimulus through even large doses of deficit expenditure cannot influence the deflation trend, at least in a direct way. Given the one-way direction of the relationship between economy and deflation, rapidly growing public debt for public measures supporting the economy, is apparently unable to influence directly the price trend. The support measures that successfully influence the economy destiny with the economic cycle improvement, in the same way can be transmitted to the negative inflation cycle, which would slow the fall. If the recovery takes then some consistency, the structural deflation can be gradually overcome.

The pricing system is therefore neutral relating to the performance of other variables, because it's a mere image of the economy. This characteristic can provide a way-out from the distressful problem of deflation. The one-way relationship from the economy to the inflation (negative in this case) offers the opportunity to observe that the image of the monetary crisis wouldn't affect the economy, playing instead the role of monitoring and reporting about the general condition of the economic system.

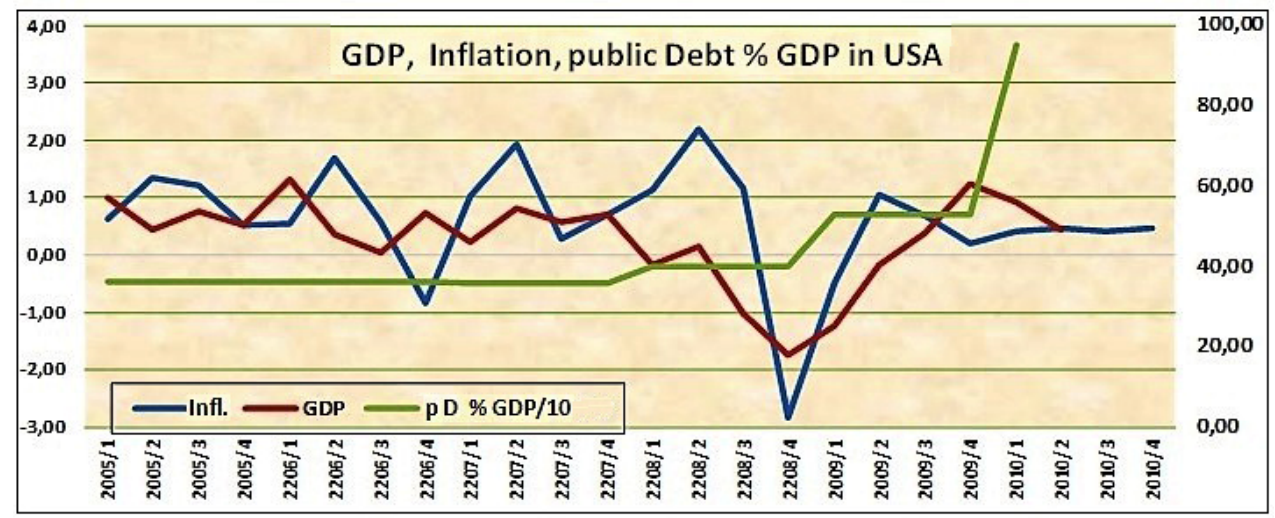

Figure 2. Inflation, GDP, Public Debt Log in million \$ in the United States

Source: based on data from IMF-“International Financial Statistics”, several years.

The Figure 2 shows the trend in USA relating to Inflation, GDP, and Public Debt as \% of GDP in the first decade of the new millennium. The performance of these three variables is indicating that, during the recovery phase of the 2009 second half, the conjuncture trend is a quarter ahead of the inflation profile. During the crisis most hard phase, can be observed instead a nearly temporal coincidence of the two cycles, moving almost in synchrony. 
Since 2010, the two variables (economy and inflation) are showing instead a progressive neutrality, coinciding with the overcoming of a deep depression.

To support the aggregate demand during the worst financial crisis since 1929, the US Public Debt has increased rapidly, from the 4th quarter of 2008 to the 4 th quarter of 2010 , going from $40 \%$ to over $90 \%$ in relation to GDP. Nevertheless, this strong acceleration, as we can see in the graph, does not affect the inflation trend, which is now low after the 2008 sharp decline, but neutral compared to the performance of the Public Debt accelerated growth.

Let's talk now about Japan, which has used Keynesian incisive manoeuvres to contain the effects of the worst financial crisis since the nineties beginning, with mixed results. After the bursting of the large speculative bubble, Japan undergoes a sharp reduction in its growth rate. In the following two decades, the country is involved in recession, because dragged by the events of the international context (in 1998 for the crisis in Southeast Asia, and in 2008 for the world global crisis). In the period 1990-2013, the continuing use of deficit public expenditure to finance new and expanded manoeuvres to support the economy, consequently caused a Public Debt rapid acceleration.

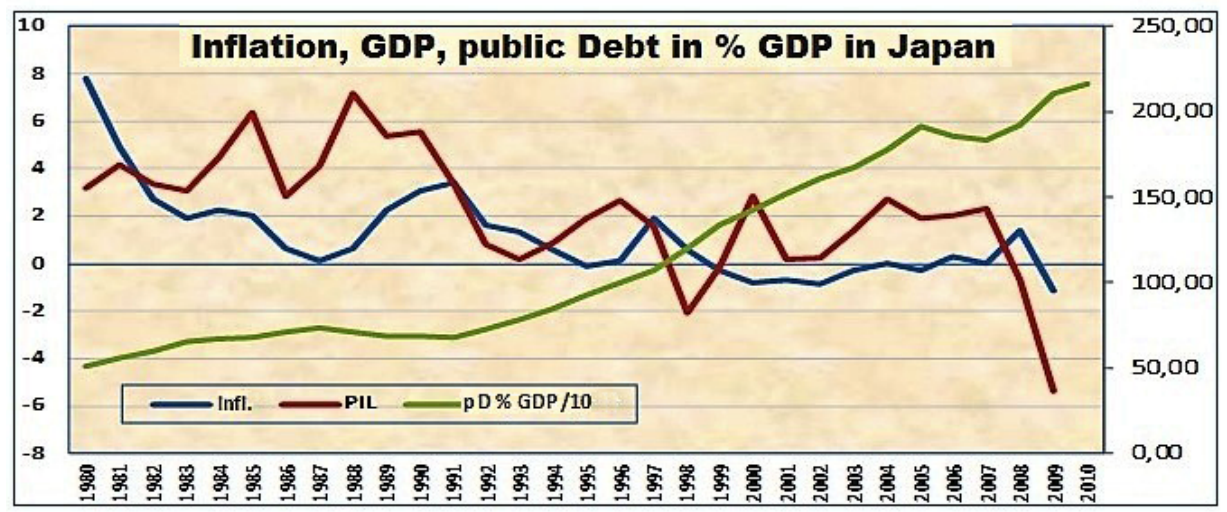

Figure 3. Inflation, GDP, Log Public Debt in \% of GDP in Japan

Source: based on data from IMF-“International Financial Statistics”, several years.

In analogy to the Figure 2 relative to the USA, this Figure 3 is showing the trend of Inflation, GDP and Public Debt in \% of GDP for Japan, during the thirty years from 1980 to 2010 . The performance of the two variables Inflation and GDP seems to confirm a clear advance in the 80s of the GDP line compared to Inflation line. The phenomenon in fact continues until the 1998 crisis (affecting the South-East Asia and involving Japan), and then continues until recent date. An accentuation of the perfect synchrony between the two variables is the sign of a crisis persistence and of a system instability increase. The graph also shows the unstoppable rise of the public debt from 1991 to 2010. It is noteworthy that already since the mid-nineties the Public Debt is exceeding the $90-100 \%$ in relation to GDP, and beyond this threshold we can see an increasing neutrality of public spending, which will grow, about the destiny of economy and prices, in deflation.

As already noticed, the economic system correction work assigned to depression, if hampered or attenuated, does not allow the return to economic stability. In the case of Japan, the clear and prolonged weakness of the economy for more than twenty years after the financial crisis could be due to some residual instability, difficult to eradicate. The financial crisis not metabolized yet after the speculative bubble in the late 80 s, the long economy slowdown in the following decade without suffering a deep recession, the constant deflation accompanying the weak economy, the progressive neutrality of the public spending impulse, all this seems to qualify a typical scenario of a protracted and untreated instability.

The Japanese experience in the past decade seems to confirm that the use of deficit public spending could have a positive impact on the economy trend, at least in the past case of a careful use of public spending and limited debt. A good proof is coming from the behaviour of the US economy in 2008-2009, following the speculative bubble explosion in the real estate sector.

In the Figure 4 are well represented the inflation trend, the GDP and the unemployment, relative to the USA during the past decade. As previously mentioned, a huge public spending program has been already activated in 
2009 to revitalize the economic situation, in deep fall. This release into the economic system of a new spending power fuelled by debt, unlike the case of Japan, does not remain inactive and without effects on the economy. Already in 2010, the curve of GDP comes again positive getting an increase of $2 \%$ with a parallel reflection on the unemployment, which also inverts its direction with a reduction of more than one point, from over $10 \%$ of 2009 to $9 \%$ of 2011 . This recovery trend will continue with growth rates exceeding the $3.5 \%$ in 2014 before declining to $2.5 \%$ in the following year, while unemployment in the same year returns to its pre-crisis levels.

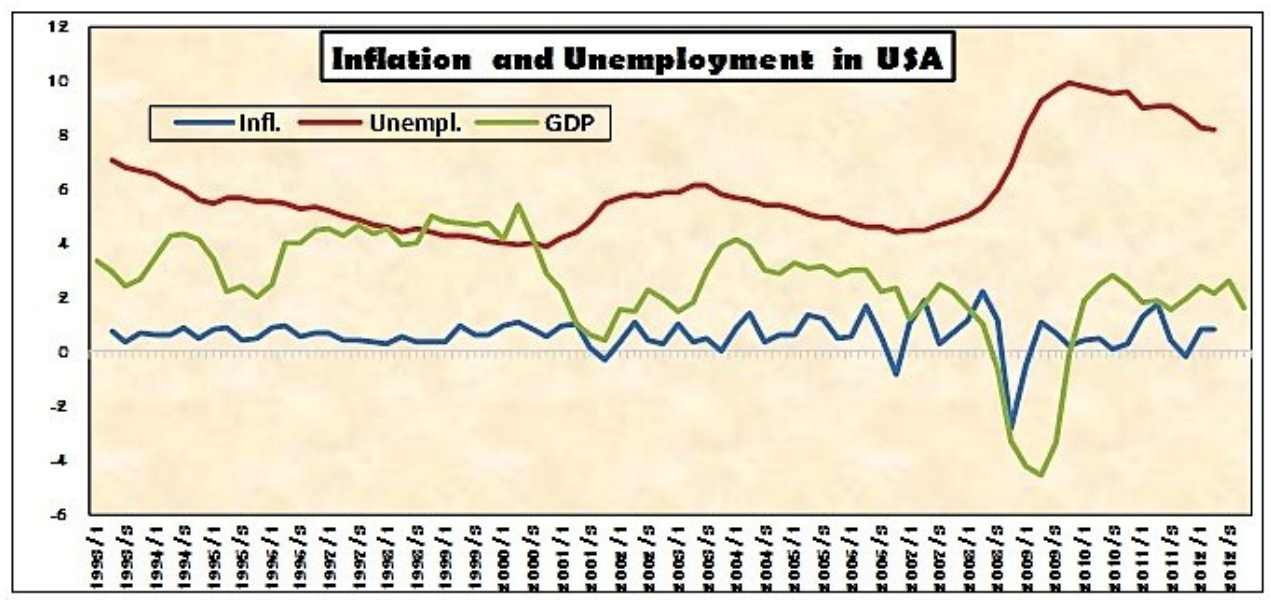

Figure 4. Inflation, GDP and unemployment in the USA during the last decade

Source: based on data from IMF-“International Financial Statistics", several years.

\subsection{The Difference of the Economy Behaviour in the USA and in Japan in Post-Financial Crisis Economy}

How to explain this evident difference of the economy behaviour in the USA and in Japan, with the use of the same instrument, the Public Debt, to support the post-financial crisis economy. The potential difference must be lying in the quantitative aspects of that Public Debt as well as in the activation timeline of the fiscal policy supporting the economy.

The core issue on which we must meditate is the obvious absurdity of trying to put out the fire with fire, or plainly speaking, it's absurd trying to mitigate the pinch of financial crisis by relying on a Public Debt increase, when this Public Debt is already in serious excess. Within an adverse context of financial crisis, to give some success chance to the action of support to the economy through the creation of new debt, it seems necessary a past virtuous conduct observed towards the public-sector indebtedness.

Going back to the two cases under analysis, at the time of the financial crisis exploded in Japan at the end of the eighties, the Public Debt related to GDP was relatively low, no more than 50\% of GDP. Nevertheless, the ratio will rise gradually until 1994, reaching a share near to 75\% (of GDP), and finally reached in the following two years the $100 \%$, which can be considered the malaise threshold for excessive indebtedness of the public sector. At this point seems to take force the paradox, that we cannot face a financial crisis caused by economic instability, emphasizing with further debt the malaise of the public sector, already over-indebted.

In the nineties, the Keynesian policy for the public support to economy in Japan reduces at the beginning of the decade the fall of the cycle, which already in 1994 starts gradually to rise again (increase of 2.3\% in 1996). The economy falls later into recession in 1998 under the blows of the Southeast Asia crisis and the austerity manoeuvre implemented by the Hashimoto government. At this point, a political crisis puts an end to the austerity experience and a new government starts a colossal spending plan, so giving wings to the public debt, which exceed the $200 \%$ in relation to GDP in 2010 . The results are partially unexpected.

The prices firstly marked a slight increase in 1997, however during the whole following decade will show a strong tendency to deflation. The economy growth at the beginning of the century is tending to the zero point, then will rise again from 2005 for the boost to exports of the "Rising Sun" country, under the impulse of the speculative boom investing the majority of the world economy. With the arrival in 2008 of the global financial crisis post-speculative boom, Japan suffered a deep recession (-5\%), though this country wasn't involved in the 
real estate exasperate speculation, which have spread in the whole industrialized West. This severe recession is another sign of the unresolved financial instability afflicting the country since the crisis of the late eighties. In the average of the years 2000-2010 both inflation and economy have marked a result lower than zero.

\section{References}

Bernanke, B. S. (2000). Essays on the Great Depression. Princeton, New Jersey: Princeton University Press.

Cardoso, E. (1992). Inflation and Poverty. In NBER Working Paper. https://doi.org/10.3386/w4006

Carmen. R., \& Rogoff, S. (2009). The Time Is Different-Eight Centuries of Financial Folly. Princeton and Oxford Kenneth: Princeton University Press.

Charles, K. (1973). The World in Depression: 1929-1939. University of California Press.

David, D., \& Wayne, F. (1979). Distribution of the Estimators for Autoregressive Time Wayne Fuller Series with an Unit Root. Journal of American Statistical Association.

Dornbusch, F. (1993). Moderate Inflation. World Bank Economic Review, 7, 1-44. https://doi.org/10.1093/wber/7.1.1

Engle, R., \& Clive, G. (n.d.). Cointegration and Error Correction: Representation, Estimation and Testing. Econometrica, 55(2).

Friedman, M. (2007). On economics—Selected Papers. University of Chicago Press.

Giovanni, C. (2016). L'inflazione, La Deflazione, Il Ciclo Economico E L'efficienza Dei Sistemi. International Multilingual Journal of Science and Technology, 1(1).

Leon, N., \& Lindberg, S. (n.d.). The Politics of Inflation and Economic Stagnation. MAIER, Brian BARRY Brookings Institution, Washington D.C.

Nicholas, W. (n.d.). The Clash that Defined Modern Economics. New York \& London: WW Norton \& Company.

Nouriel, R. (n.d.). Crisis Economics: A crash Course in the Future of Finance. Stephen MIHM.

Nouriel, R., Alesina, A., \& Cohen, O. G. (1997). Political Cycles and the Macroeconomy. MIT Press.

Paul, R. K. (n.d.). The return of depression economics and the crisis 2008. W.W. Norton \& Company.

Peter, T. (n.d.). Lessons from the Great Depression. Cambridge, Massachusetts: The MIT Press.

Sargent, T. J. (n.d.). The Ends of Four Big Inflation. In H. Robert (Ed.), Inflation: Causes and Effect. University of Chicago Press.

Schumpeter, J. (1939). Business Cycles: A theoretical, historical and statistical analysis of the Capitalist process. New York, Toronto, London: McGraw-Hill Book Company.

Shilling, A. G. (2001). Deflation. How survive and thrive in coming wave of deflation.

Stephen, S. R. (2009). The next Asia-Opportunities and challenges for a new globalization. John Wiley \& Sons, Inc.

Stock, J. H., \& Watson, M. W. (1993). A simple estimator of cointegrating vectors in higher order integrated systems. Econometrica: Journal of the Econometric Society. https://doi.org/10.2307/2951763

Thomas, F., \& Cargill, T. (1997). The political economy in Japanese monetary policy. Hutchison, Massachusetts Institute of Technology.

Timothy, F. G. (n.d.). STRESS TEST—Reflections on Financial Crises. In RH Business Books.

\section{Copyrights}

Copyright for this article is retained by the author(s), with first publication rights granted to the journal.

This is an open-access article distributed under the terms and conditions of the Creative Commons Attribution license (http://creativecommons.org/licenses/by/4.0/). 